(c) American Dairy Science Association, 2002.

\title{
Peptides From the N-terminal End of Bovine Lactoferrin Induce Apoptosis in Human Leukemic (HL-60) Cells
}

\author{
M. K. Roy, ${ }^{*}$ Y. Kuwabara,† K. Hara,† Y. Watanabe, ${ }^{\star}$ and Y. Tamai ${ }^{\star}$ \\ Department of Biological Chemistry, Faculty of Agriculture, \\ Ehime University, Japan 790-8566 \\ †Shikoku Milk Product Co. Ltd. Kawauchi, Ehime, Japan. 791-0397
}

\section{ABSTRACT}

To determine the effects of the multifunctional ironbinding glycoprotein, lactoferrin (LF) and related compounds on the growth of leukemic cells, human myeloid leukemic cells (HL-60) were exposed to bovine lactoferrin (bLF) and proteolytic hydrolysates of bLF. Pepsin hydrolysates of bLF showed a greater growth suppressive effect than tryptic hydrolysates or mature bLF. Four peptides with proliferation inhibition activity were purified from pepsin hydrolysates by ion-exchange chromatography, reverse-phase HPLC, and gel-filtration. All peptides were from the $\mathrm{N}$-terminal end, in a region where lactoferricin $B$ (Lfcin $B$ ), an antibacterial peptide, is located. Among the four peptides, peptide 1 (pep1) was found to exhibit highest activity and corresponded to residues 17 to 38 of bLF, with a molecular weight of 2753.88 . The $\mathrm{IC}_{50}$ value of this peptide was $6.3 \mu \mathrm{g} / \mathrm{ml}$. Three other peptides were less active and corresponded to sequences 1 to 16 and 45 to 48 , linked by disulfide-bridge (pep2, molecular mass of 2430.13), 1 to 15 and 45 to 46 linked by disulfide bridge (pep3, molecular mass of 2017,92) and from residues 1 to 13 (pep4, molecular mass of 1558.73). Cell proliferation inhibition activity of the peptides was thought to be due to induction of apoptosis, which was evaluated by DNA ladder formation, DNA fragmentation, enhanced expression of phosphatidyl serine, and morphological changes. The $\mathrm{IC}_{50}$ values of the three peptides were confirmed using synthetic peptides and were consistent with those of purified peptides.

(Key words: bovine lactoferrin, apoptosis, leukemic cells)

\begin{abstract}
Abbreviation key: bLF = bovine lactoferrin, FITC = fluorescein isothiocyante, pep $=$ peptide, $\mathbf{P I}=$ propidium iodide, RP-HPLC $=$ reverse-phase HPLC, TBE = $89 \mathrm{~m} M$ Tris, $89 \mathrm{~m} M$ boric acid, and $2 \mathrm{~m} M$ EDTA buffer, TFA $=$ trifluoroacetic acid.
\end{abstract}

Received October 10, 2001.

Accepted November 12, 2001.

Corresponding author: Y. Tamai; e-mail: tamai@agr.ehime-u.ac.jp

\section{INTRODUCTION}

Apoptosis is a distinct form of cell death that is considered to play important roles in embryogenesis (Pierce et al., 1989), carcinogenesis (Vaux et al., 1988), regulation of maturation of the immune system (Ucker, 1987), and cytotoxic cell killing of virally infected cells (Laurent-Crawford et al., 1991). The cell death is characterized by distinct morphological changes, including nuclear condensation and digestion, membrane blebbing, and formation of apoptotic bodies.

Bovine milk, especially the protein fraction, has been shown to contain numerous substances that contain biologically active components that are released upon enzymatic proteolysis during fermentation or gastrointestinal digestion. In a previous study, we reported that bovine milk digested with protease B of Saccharomyces cerevisiae induced apoptosis in human leukemic cell (Roy et al., 1999). Lactoferrin is an iron-binding glycoprotein present in milk and many other biological fluids of mammals including saliva, tears, and mucous secretions, and is released from activated neutrophils in the inflammatory response. Lactoferrin is widely considered to be an important component of the host defense against microbial infection. Among its biological functions, the antimicrobial activity has been extensively investigated (Bellamy et al., 1992a, 1992b, 1993; Dionysisus and Milne, 1997). Other biological functions attributed to lactoferrin include roles in modulation of the inflammatory response, activation of the immune system, and control of myelopoiesis (Brock, 1995). Its antimicrobial property has been assigned to its ability to chelate iron essential for bacterial growth (Arnold et al., 1977). In addition, it has been shown to alter the permeability of the outer cell membrane of the Gramnegative bacteria (Ellison et al., 1988, 1989). The microbial killing effects of pepsin-generated peptides have been shown to be 10- to 100-fold stronger than that of undigested lactoferrin. Several peptides with antimicrobial activity have been identified from pepsin-generated hydrolysate (Dionysius and Milne, 1997; Recio et al., 1999). However, there have been very few reports of isolation and identification of peptides from bovine lactoferrin (bLF) with other biological functions. 
The HL-60 human promyelocytic leukemia cell line has been well characterized as an in vitro model for cell proliferation. Previously, we reported that fermented milk cultured with various lactic acid bacteria, including yeast, suppressed the growth of HL-60 cells (Ito et al., 1998). In this study, we investigated whether the cytotoxic properties of pepsin-generated peptides of bLF on the growth of HL cells were due to the induction of apoptosis. Several chromatographic techniques were applied to isolate these peptides from pepsin hydrolysates of bLF. First, bLF was digested with pepsin and the hydrolyzed materials were fractionated by ion-exchange chromatography. Then, reverse-phase HPLC (RP-HPLC) was used, followed by gel-filtration on an HPLC GS-320 column. We report here that a peptide almost identical to Lfcin B and three other cationic peptides from the N-terminus of bLF, generated by peptic cleavage, contribute to the cytotoxic activity. The latter three are novel peptides and have not previously reported to be cytotoxic. Activity of the purified peptides was confirmed by chemically synthesized peptides. The cytotoxic activity of the purified peptides was examined with DNA ladder test, DNA fragmentation assay, phosphatidyl serine expression, and morphological changes.

\section{Materials and Methods}

\section{Materials}

Bovine lactoferrin was obtained from Wako Pure Chemicals Ltd., Japan. Pepsin was obtained from Sigma Chemical Co. (St. Louis, MO).

\section{Pepsin Digestion of bLF}

A $5 \%$ aqueous solution of bLF was adjusted to $\mathrm{pH}$ 3.0 with $1 \mathrm{~N} \mathrm{HCl}$ and digested with $1 \%$ (by weight of substrate) porcine pepsin A (EC 3.4.23.1, 4,550 U/mg of solid) for $4 \mathrm{~h}$ at $37^{\circ} \mathrm{C}$. The reaction was terminated by heating at $90^{\circ} \mathrm{C}$ for $8 \mathrm{~min}$, and the $\mathrm{pH}$ was adjusted to 7.0 by addition of $1 \mathrm{~N} \mathrm{NaOH}$. The digest was centrifuged at $15,000 \times g$ for $10 \mathrm{~min}$, and the supernatant was retained and freeze-dried.

\section{Purification and Characterization of Peptides}

Ion-exchange chromatography. The bLF hydrolysate, prepared as described above, was dissolved in distilled water, and $2 \mathrm{ml}$ was injected onto a column (150 $\times 26 \mathrm{~mm} \mathrm{I}$. D.) of SP-Sepharose Fast Flow resin (Pharmacia LKB Biotechnology, Uppsala, Sweden) equilibrated at $4^{\circ} \mathrm{C}$ with $10 \mathrm{mM}$ ammonium bicarbonate buffer ( $\mathrm{pH}$ adjusted to 7.0 with concentrated ammonia solution). Peptides were eluted at a flow rate of $2 \mathrm{ml} / \mathrm{min}$ in 150 min with a 0 to $100 \%$ gradient of $4 M$ ammonia solution. The column was then washed with the starting buffer, and then peptides were eluted with a 0 to $100 \%$ gradient of $2 M \mathrm{NaCl}$.

$\boldsymbol{R P}-\boldsymbol{H P L C}$. All the fractions obtained on ion-exchange chromatography were desalted by HPLC on a Waters type Cosmosil 5C18-AR (Nacalai Tesque Inc., Kyoto, Japan) reverse-phase column. The column was equilibrated with $0.05 \%$ trifluoroacetic acid (TFA; solvent $\mathrm{A}$ ), and the sample adjusted to $0.05 \% \mathrm{TFA}$ was loaded at $1 \mathrm{ml} / \mathrm{min}$. The peptide material was washed with solvent A until the baseline returned to zero and was then eluted with solvent B $(90 \%$ acetonitrile in $0.05 \%$ TFA). The absorbance of the column eluent was monitored continuously at $220 \mathrm{~nm}$. Desalted peptide material was lyophilized and tested for activity for further analysis. The peptides were fractionated by HPLC using an analytical reverse-phase column (TSK GEL ODS 80 Ts, Tosoh Co., Tokyo, Japan). Samples were loaded onto the column previously equilibrated with solvent A, and the column was washed extensively with the solvent. Peptides were eluted using a gradient of solvent B from 0 to $80 \%$ over 60 min at a flow rate of 1 $\mathrm{ml} / \mathrm{min}$. Fractions were collected according to the peaks of separated peptides and were lyophilized. Pooled peptide peaks were tested for activity, and those with high activity were further purified by gel filtration. Lyophilized peptides peaks were dissolved in ammonium acetate buffer ( $\mathrm{pH}$ was adjusted to 7.0 with concentrated ammonia solution) and applied to a gel-filtration column (Asahipak GS320HQ; Asahi Chemical Industry, Tokyo, Japan), and eluted with the same ammonium acetate buffer at a flow rate of $1 \mathrm{ml} / \mathrm{min}$. The elution was monitored at $220 \mathrm{~nm}$. For further purification, the lyophilized peptide samples were applied on ODS 80 Ts column for another round of reverse-phase chromatography as described above. Purified peptides were lyophilized and stored at $-20^{\circ} \mathrm{C}$.

$\boldsymbol{N}$-Terminal sequence analysis. The $\mathrm{N}$ terminal sequence of the purified peptides was identified by sequence analysis with a gas-phase sequencer (model PSQ-2, Shimadzu, Kyoto, Japan).

Mass spectrometry. The mass of each purified peptide was measured by mass spectrometry (Voyager DEPro, Applied Biosystems, Birmingham, MA). The samples were dissolved in $50 \%$ acetonitrile containing $0.1 \%$ TFA and $5 \mathrm{mg} / \mathrm{ml}$ of $\alpha$-cyano-4-hydroxycinnamic acid to a concentration $10 \mu \mathrm{g} / \mathrm{ml}$. A sample of $1 \mu \mathrm{l}$ was injected into the solvent delivery system using a flow of $50 \%$ acetonitrile at $4 \mu \mathrm{l} / \mathrm{ml}$. The mass spectrometer was operated in positive ion reflector mode (acceleration voltage, 15000). Using GRAMS (Galatic) software molecular masses of the charged particles were calculated.

Assay for cell proliferation inhibition activity. Human acute myeloid leukemia (HL-60) cells were ob- 
tained from the Japanese Cancer Research Resources Bank and routinely cultured in RPMI-1640 medium as described previously (Ito et al., 1998). Cell proliferation activity was measured with cell titer 96 aqueous nonradioactive cell proliferation assay (MTS assay). Cell suspensions were treated with peptides and after culture for 4 to $48 \mathrm{~h}$ at $37^{\circ} \mathrm{C}$, a solution of (3-(4,5-dimethylthiazol-2-yl)-5-(3-carboxymethoxyphenyl)-2-(4-sulfophenyl)-2H-tetrazolium (MTS) and phenazine methosulfate was added and culture was continued for an additional $4 \mathrm{~h}$. The absorbance was measured at 490 $\mathrm{nm}$ on 96 -well plates with a micro-plate reader.

Morphological examination. HL-60 cells $\left(1 \times 10^{6}\right)$ incubated for $24 \mathrm{~h}$ in the presence of purified or synthetic peptides $(100 \mu \mathrm{g} / \mathrm{ml})$ were observed by light microscope.

DNA fragmentation assay. HL-60 cells $\left(1 \times 10^{6}\right)$ were treated with the synthetic peptides $(100 \mu \mathrm{g} / \mathrm{ml})$ for $24 \mathrm{~h}$, then harvested and washed twice with icecold PBS. The DNA was extracted with an ApopLadder Ex kit, (Takara Biomedicals, Osaka, Japan). DNA fragments were loaded onto a 1.5\% agarose gel in TBE buffer ( $89 \mathrm{~m} M$ Tris, $89 \mathrm{~m} M$ boric acid, and $2 \mathrm{~m} M$ EDTA) and electrophoresed at a constant voltage of $100 \mathrm{~V}$. The gels were stained with ethidium bromide and photographed on an UV transilluminator.

Quantification of DNA fragmentation. The extent of DNA fragmentation was determined as previously described (Brunk et al., 1979; Wyllie, 1980). Briefly, aliquots of $1 \times 10^{5}$ cells suspended in $5 \mathrm{ml}$ of RPMI medium containing $100 \mu \mathrm{g} / \mathrm{ml}$ of peptide were incubated for $6,12,24$, and $48 \mathrm{~h}$ at $37^{\circ} \mathrm{C}$ in a humidified atmosphere containing $5 \% \mathrm{CO}_{2}$. After incubation, cells were collected by centrifugation and lysed by incubation in $2 \mathrm{ml}$ of $0.5 \%$ Triton X-100 containing $5 \mathrm{~m} M$ Tris- $\mathrm{HCl}$ (pH 7.4) and $1 \mathrm{mM}$ EDTA for $20 \mathrm{~min}$ on ice. The lysate and the supernatant obtained after centrifugation at $27,000 \times g$ for 20 min were sonicated for $40 \mathrm{~s}$, and analyzed for DNA content with the fluorescent reagent (100 mM NaCl, $10 \mathrm{~m} M$ EDTA, and $10 \mathrm{~m} M$ Tris, $\mathrm{pH}$ 7.0 containing $100 \mathrm{ng} / \mathrm{ml}$ of DAPI). The percentage of fragmented DNA was defined as the ratio of DNA content of the supernatant to that of the lysate multiplied by 100 .

Flow cytometric assay for phosphatidyl serine expression. Phosphatidyl serine, located in the inner leaflet of the cell membrane, is exposed at the cell surface in the early stage of apoptosis. Annexin V shows high-affinity phosphatidyl serine-binding that makes it a useful selective and powerful tool for detection of apoptotic cells. Aliquots of $1 \times 10^{6}$ cells were washed in ice-cold PBS buffer and suspended in binding buffer (Annexin V FITC kit, Immunotech, France). Annexin V fluorescein isothiocyante (FITC) and propidium iodide

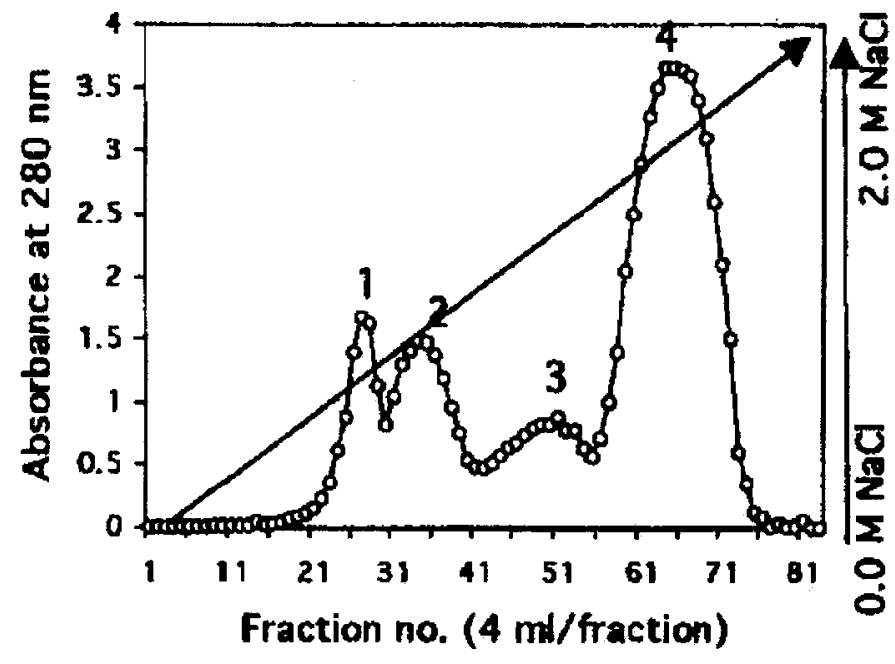

Figure 1. Ionexchange chromatography of pepsin digested bovine lactoferrin. Samples were applied to a Hiload type (26/10) SP-sepharose Fast Flow column, and gradient elution was conducted by applying an increasing concentration of 0 to $2 M \mathrm{NaCl}$. Before elution, the column was washed with starting buffer and then with $4 M$ ammonia solution.

(PI) were added to the cell suspension, and the mixture was incubated for $10 \mathrm{~min}$ on ice in the dark. The stained cells were analyzed using a FACScan flow cytometer (model FACS Calibur, Becton Dickinson, CA). Annexin V-FITC-generated signals were detected with an FITC signal detector (FL1, $525 \mathrm{~nm}$ ). The PI signals were monitored using a detector reserved for phycoerythrin emission (FL2, $575 \mathrm{~nm}$ ).

\section{RESULTS}

\section{Purification of Peptides with Cell Proliferation Inhibition Activity}

Pepsin hydrolysate of bLF was found to inhibit cell proliferation more strongly than undigested protein. In a preliminary experiment, $500 \mu \mathrm{g} / \mathrm{ml}$ of bLF hydrolysate was shown to inhibit cell proliferation by $50 \%$ as measured by MTS assay.

The bLF hydrolysate was fractionated by fast-flow SP-Sepharose column chromatography, and, after desalting, the cell proliferation inhibition activity of each fraction was examined by MTS assay. In the first step of chromatography, some activity was detected in the void fraction and $4 M$ ammonia fraction but main activity was found in the fractions eluted with gradient elution of 0 to $2 \mathrm{M} \mathrm{NaCl}$. During this elution, four peaks were obtained (1, 2, 3, 4 in Figure 1), which were analyzed by RP-HPLC. The first peak (1, Figure 1) was fractionated into several components when resolved by 
RP-HPLC (Figure 2C). All the peaks were tested but three (1, 2, and 3 in Figure 2C) of them showed activity to inhibit the growth of HL-60 cells. However, the fourth (4, Figure 1) peak was shown to be essentially pure in the RP-HPLC (peak 1 in Figure 2A) with activity. The resolved active peaks obtained after RP-HPLC were purified further by HPLC on a GS-320 column and most of the activity was recovered from the main peak. Finally, the peptide fractions obtained after the second round of RP-HPLC were subjected to mass spectrometry, sequence analysis, and activity assay.

The desalted 2 and 3 fractions (Figure 1) were also resolved by RP-HPLC and several peaks with proliferation inhibition activity were obtained (data not shown). Then, the peaks were subjected to amino acid sequence analysis.

Cell proliferation inhibition activity of purified peptides. Human leukemia HL-60 cells were exposed to $200 \mu \mathrm{g} / \mathrm{ml}$ of the peptides (pep1, pep2, and pep4) for the indicated times, or to various concentrations of purified peptides for $48 \mathrm{~h}$, and then cell proliferation inhibitory activity or cell viability was determined by MTS assay. The proliferation inhibition activity of the purified peptides toward HL-60 cells is shown in Table 1 and in Figure 3A. Percentage of cell viability is expressed in Figure 3B. Proliferation inhibition was calculated in terms of reduction of MTS, and the concentrations for $50 \%$ growth inhibition $\left(\mathrm{IC}_{50}\right)$ are shown in the Table 1. The values of $\mathrm{IC}_{50}$ are expressed on a molar and $\mu \mathrm{g} / \mathrm{ml}$ basis. From this table, it can be seen that all the peptides inhibited the growth of HL-60 cells with various degrees of inhibitory activity. Pep1 exhibited the highest activity. Pep2, with the amino acid sequence of pep4 in the first 13 amino acid residues, exhibited slightly stronger activity than pep4. In terms of cell proliferation, inhibitory activity, pep 1 was 6 - to 10 -fold more active than pep2 and pep4 during 24 - to 48 -h incubation.

\section{Characterization of Peptides}

After confirming cell proliferation inhibition activity, the fractions containing essentially one single peak on RP-HPLC were subjected to mass spectrometry, and sequence analysis. Peak (pep1) in Figure 2B was very similar to Lfcin B-a bactericidal peptide the sequences of which corresponded to amino acid residues 17 to 41 of bLF. Pep 1 corresponded to the amino acids 17 to 38 of the mature protein and had a molecular mass of 2753.88 as determined by mass spectrometry (Figure $4 \mathrm{~A}$ ), which was consistent with the mass calculated from the amino acid sequence. The amino acid sequence of peptide 2 (pep2, peak in Figure 2D) corresponded to residues 1 to 16 and 45 to 48 , and the two peptides
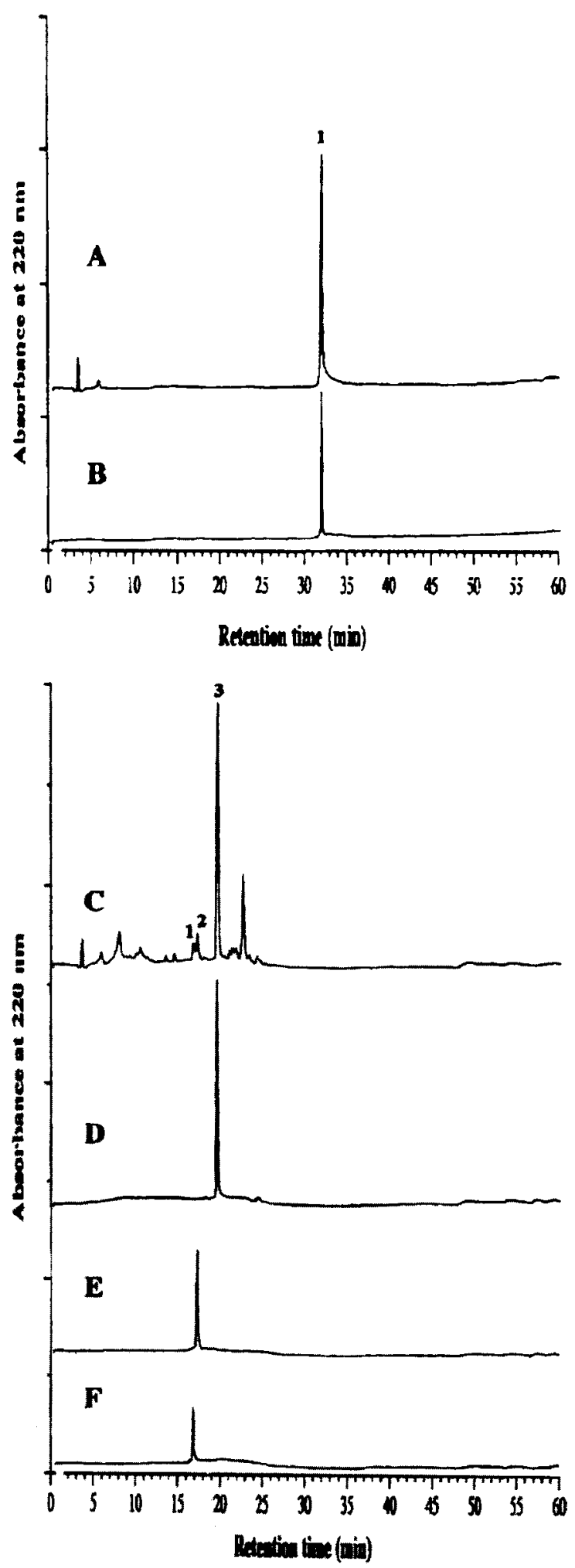

Figure 2. Reverse-phase HPLC chromatogram of the elution peaks, obtained during the elution of the SP-Sepharose Fast Flow column, and purified peptides. (A), fraction 4; (B), purified peptide 1 (pep1). (C), fraction 1; (D), purified peptide 2 (pep2); (E), purified peptide 3 (pep3); (F), purified peptide 4 (pep4). 
Table 1. Amino acid sequence of the cell proliferation inhibitor from pepsin-digested lactoferrin and the concentration of the inhibitor needed to inhibit the cell proliferation by $50 \%$.

\begin{tabular}{llccrr}
\hline $\begin{array}{l}\text { Peptide } \\
\text { No. }\end{array}$ & N-terminal sequence & $\begin{array}{c}\text { Position in } \\
\text { lactoferrin }\end{array}$ & $\begin{array}{l}\text { Molecular } \\
\text { mass }\end{array}$ & $\mu M$ & $\mu \mathrm{g} / \mathrm{ml}$ \\
\hline $\begin{array}{l}\text { Peptide } \\
\begin{array}{l}1 \\
\text { Peptide }\end{array}\end{array}$ & FKCRRWQWRMKKLGAPSITCVR & $17-38$ & 2753.88 & 2.22 & 6.1 \\
$\begin{array}{l}\text { Peptide } \\
3\end{array}$ & APRKNVRWCTISQPEW CIRA & $(1-16)-(45-48)$ & 2430.13 & 11.9 & 28.9 \\
$\begin{array}{l}\text { Peptide } \\
4\end{array}$ & APRKNVRWCTISQPE CI & $(1-15)-(45-46)$ & 2017.92 & ND & ND \\
\hline
\end{tabular}

were linked by a disulfide bond. Mass spectrometry analysis showed that the peptide had a molecular mass of 2430.13 (Figure 4B), which was consistent with the data obtained from sequence analysis. Mass spectrometry of the peptide (pep3) obtained in the peak as shown in Figure 2E showed a molecular mass of 2017.92 (Figure $4 \mathrm{C}$ ). This matched with the calculated value obtained from sequence data-amino acid residues 1 to 15 and 45 to 46 linked by a disulfide bond. Peptide 4 (pep4, peak in Figure 2F) corresponded to residues 1 to 13 of bLF and had a molecular mass of 1558.73 (Figure 4D). We identified (data not shown) two active peptides in the fraction 3 of SP-Sephacel Chromatography (Figure 1), which corresponded to 17-36 and 17-38 resi-
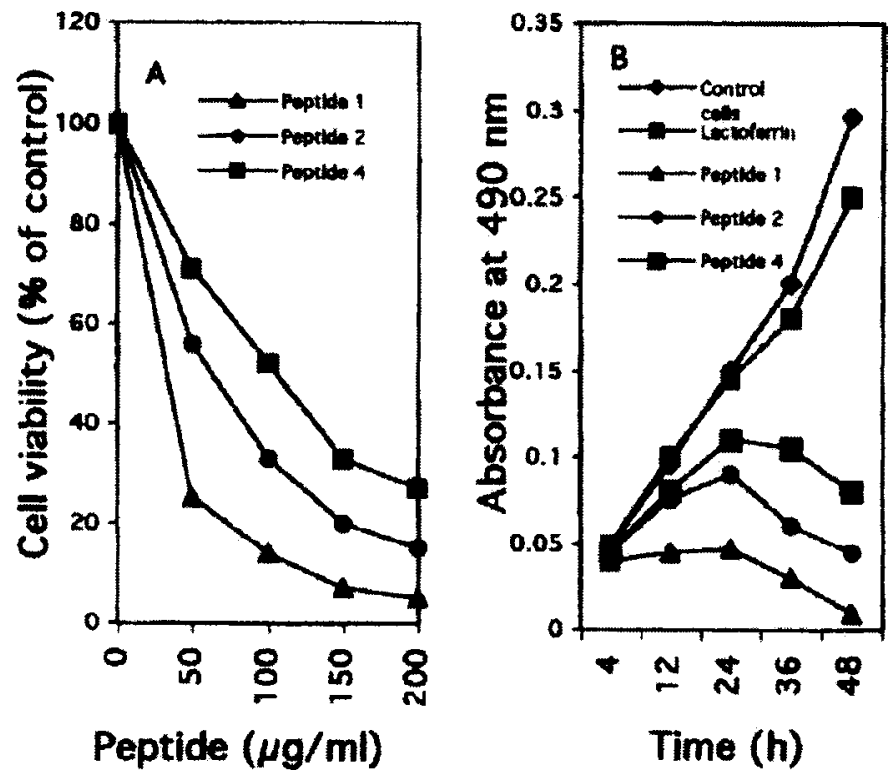

Figure 3. Dose and time dependence of growth inhibition in HL60 cells treated with the purified peptides. (A), Cells were treated with increasing concentration of the purified peptides $(48 \mathrm{~h})$. (B), cells were incubated with $200 \mu \mathrm{g}$ of purified peptides for the indicated times. Cell growth and percentage of cell viability were examined by MTS assay. dues respectively of bLF. These two peptides were very similar to the peptide obtained in fraction 4 , and were not considered for further study. Another peptide with the amino acid sequence WRMKKLGAPSITCVR was also identified in the same fraction. This peptide corresponded to the fragment 24 to 37 of bLF. Due to its low purity and dissimilarity in the value of mass spectrometry with the calculated molecular mass obtained from sequence analysis, the potency of this peptide was not examined.

Induction of DNA fragmentation. To determine whether the features of cell death induced by the peptides as described above were those of apoptosis or necrosis, we performed agarose gel electrophoresis of DNA extracted from HL-60 cells that had been treated with $100 \mu \mathrm{g} / \mathrm{ml}$ for $24 \mathrm{~h}$. As shown in Figure 5A, HL-60 cells treated with the peptides showed the ladder of DNA fragmentation that is characteristics of apoptosis. However, a smear of DNA fragmentation was also observed only when the cells were treated with pep1, which indicates that some population of the cells died due to the necrotic activity of pep1. The extent of DNA fragmentation induced by the above peptides was quantified by a method that involved staining with DAPI (Figure 5B). HL-60 cells treated with each of the purified peptides exhibited significant increases of DNA fragmentation during 24 to $48 \mathrm{~h}$ incubation. However, under the same experimental conditions, pep1 was more effective than pep2 or pep4 on a $\mu \mathrm{g} / \mathrm{ml}$ basis.

Flow cytometry analysis. To confirm the type of cell death induced by pep1 and pep2, cells were stained with both PI and FITC-labeled annexin V, which binds phosphatidyl serine, and then analyzed by flow cytometry (Table 2, Figure 6). In Figure 6, the lower left population of cells that have low level of FITC and PI signals in each plot indicates viable cells. Those in the upper left, which have low FITC and high PI signals, indicate necrotic cells. The lower right and upper right populations correspond to apoptotic and secondary necrotic, which have high FITC and low PI, and high FITC and 


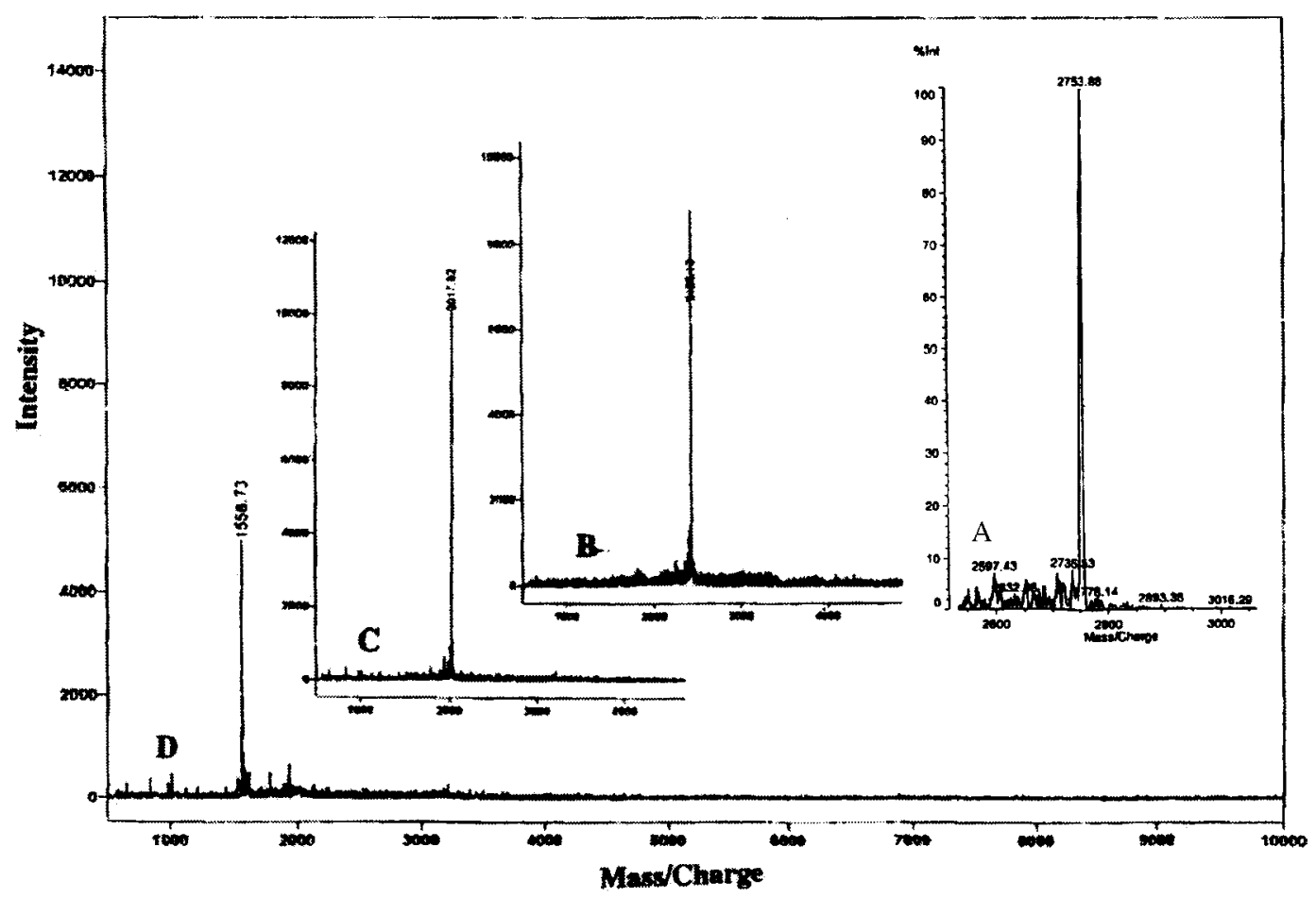

Figure 4. Electrospray mass spectra of the peptide-fractions shown in Figure 2. (A), pep1; (B), pep2; (C), pep3; (D), pep4.

high PI signals, respectively. More than $90 \%$ of the untreated control cells were annexin and PI negative (Figure $6 \mathrm{~A}$ ), whereas an increase in the lower right population was observed (Figure 6, E and F) at $6 \mathrm{~h}$ when the cells were incubated with pep1 and pep2. For pep1, a significant increase in the upper right population was observed after $24 \mathrm{~h}$ of incubation, whereas the lower right population in pep2 cells became clearer at 24 $\mathrm{h}$ of incubation. The annexin-positive and PI-negative cells corresponded to apoptotic cells (lower right cells), while those positive for both are likely to be derived from the lower right population and became secondary necrotic (late apoptotic) cells (upper right population, Figure 6D). Treatment with pep2 suggested that a longer incubation period is needed for cells to change from apoptotic to secondary necrotic state.

Morphological changes induced by the peptides. We also examined the morphological appearance of the cells, and it can be noticed that HL-60 cells underwent marked morphological changes upon treatment with pep1 or other purified peptides. As shown in Figure 7 (B and C), the cells exposed to pep1 and pep2 displayed morphological changes compatible with apoptosis (cell shrinkage, nuclear condensation, appearance of apoptotic bodies), whereas untreated control cells remained morphologically normal (Figure 7A).

\section{Discussion}

In our studies to elucidate the biological properties of bovine milk, we showed that bovine milk contains biochemical factors with potent cytotoxic properties against some of tumor cells (Ito et al. 1998). The active factors are mostly inactive within the structure of the precursor compounds but can be released by enzymatic proteolysis. This study provided further evidence that milk components could play a role in suppressing uncontrolled growth of leukemic cells. As a bactericidal protein, and because of its inhibitory roles against pathogens, and because of many other physiological properties, lactoferrin was considered for a follow-up investigation to identify the possible cytotoxic factors derived from milk protein. Primarily, the pepsin hydrolysate of bLF was found to be more effective in inhibiting the growth of leukemic cells than the other proteolytic hydrolysates. Here, we characterized three peptides from pepsin-digested bLF that inhibited the proliferation of human leukemic cells (HL-60) to various degrees. All the peptides were derived from the N-terminus and were contained in the first 48 residues from the $\mathrm{N}$-terminal end of bLF. Lfcin B, corresponding to residues 17 to 41 of bLF (Bellamy et al, 1992a) was shown to be involved in the antibacterial mechanism of action of bLF. In this study, Pep1, which was found 

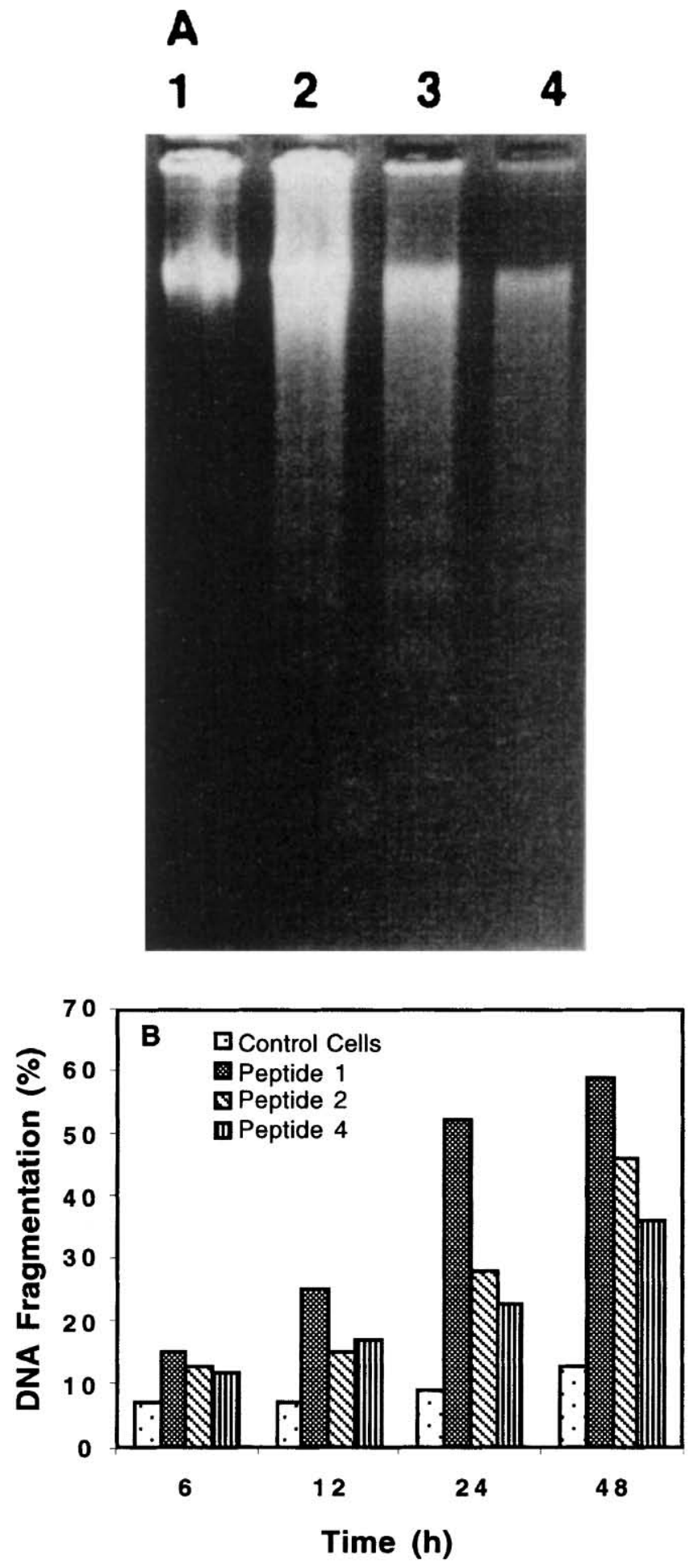

Figure 5. Apoptosis induced by the peptides purified from pepsin hydrolysates of bLF. (A), apoptotic DNA ladder at $24 \mathrm{~h}$ after treatment with pep1 (lane 2), pep2 (lane 3), pep3 (lane 4) or no peptides (lane 1); (B), The percentage of DNA fragmentation in HL-60 cells induced by the purified peptides. Cells were treated for various times with $100 \mu \mathrm{g} / \mathrm{ml}$ of purified peptides. The extent of DNA fragmentation was determined by the DAPI method as described in Materials and Methods.
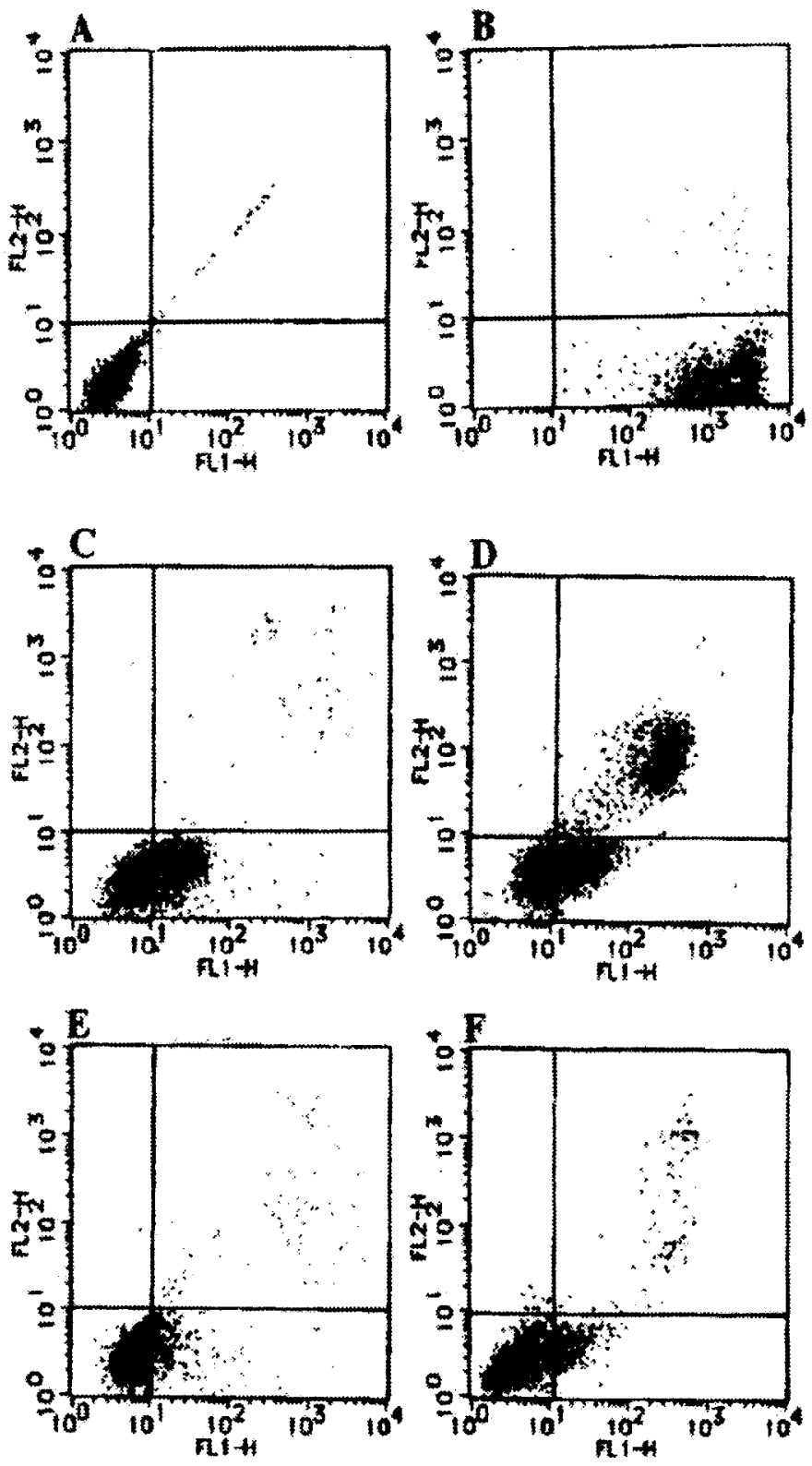

Figure 6. Flow cytometric analysis of HL-60 cells after staining with annexin V FITC/PI. HL-60 cells were treated with $200 \mu \mathrm{g} / \mathrm{ml}$ of purified peptides for 6 or $24 \mathrm{~h}$. Cells were incubated with no sample (A), 3\% formaldehyde (B), pep1 for $6 \mathrm{~h}$ (C), pep1 for $24 \mathrm{~h}$ (D), pep2 for $6 \mathrm{~h}(\mathrm{E})$, pep2 for $24 \mathrm{~h}(\mathrm{~F})$. In the figures, X-axis (FL1-H) indicates Annexin V, Y-axis (FL2-H) indicates propidium iodide.

to be most effective in inhibiting the proliferation of HL-60 cells, corresponded to residues 17-38 of native $\mathrm{bLF}$. This peptide differed by three amino acid residues at the carboxyl terminus from Lfcin B. Our study, which consisted amino sequence, molecular mass analysis, revealed two other similar peptides corresponded to residues 17-36 and 17-37 (data not shown) of mature bLF with similar functions to pep1. These results showed 
Table 2. Summery of cell flow cytometric analysis of HL-60 cells treated with formaldehyde, pep1, and pep2.

\begin{tabular}{lllllr} 
Sample & $\begin{array}{l}\text { Incubation } \\
\text { time }(\mathrm{h})\end{array}$ & $\begin{array}{l}\text { Viable cell } \\
(\%)\end{array}$ & $\begin{array}{l}\text { Apoptotic } \\
\text { cell }(\%)\end{array}$ & $\begin{array}{l}\text { Necrotic } \\
\text { cell }(\%)\end{array}$ & $\begin{array}{l}\text { Secondary } \\
\text { necrotic cell } \\
(\%)\end{array}$ \\
\hline $\begin{array}{l}\text { No sample } \\
\text { (Nontreated cells) }\end{array}$ & 6 & & & & \\
3\% Formaldehyde & 0.5 & 96 & 0.3 & 0.1 & 3.6 \\
Pep1 & 6 & 0.4 & 96.5 & 0.1 & 3.0 \\
Pep1 & 24 & 33.1 & 64.3 & 0.5 & 2.1 \\
Pep2 & 6 & 32.5 & 45.7 & 0.6 & 21.2 \\
Pep2 & 24 & 70.5 & 24.6 & 0.4 & 4.5 \\
\hline
\end{tabular}

that residues, around 36-42 of mature lactoferrin split readily by the action of pepsin and various Lfcin B-like peptide fragments can be formed that differ in one, two, or three amino acid residues at the carboxyl terminal end. Furthermore, these observations suggested that after deletion of one, two, or three amino acid residues from the carboxyl terminal end of Lfcin B, the molecular configuration responsible for proliferation inhibition activity will be affected very little.

Pep2 contained the amino acid sequences $\mathrm{f}(1-16)-\mathrm{f}(45-$ 48), which can be compared to a bactericidal peptide (Dionysius and Milne, 1997) and has not previously been reported to have cytotoxic activity. Although this peptide was not as potent as pep1, it clearly suppressed the growth of HL-60 cells. A peptide (pep3 in Table 1) with almost the same amino acid sequence (f(1-15)-f(4546)) was also identified to have similar function and showed a molecular mass of 2017.92. Pep4 was found to contain residues 1 to 13 residues of native $\mathrm{bLF}$ and exhibited weaker activity than pep1 and pep2. Amino acid sequence and mass spectrometry analysis of all of the above peptides demonstrated that several regions of mature bLF could suppress the growth of leukemic cells. However, the low $\mathrm{IC}_{50}$ value of the mature protein can be explained by poor exposure of possible active sequences of bLF to the target sites on cell surface. However, the discrepancies in the cytotoxic activity between pep1 and two other peptides (pep2 and pep4) would further explain that a much smaller molecule might not have higher accessibility to the target sites on the cell surface to suppress the growth of leukemic cells. This observation suggested the availability of a smaller fragment with much more activity in inhibiting the cell proliferation, and thus it is important to find the fragment with highest potency for future chemical design and synthesis of cytotoxic agents. Further stud-
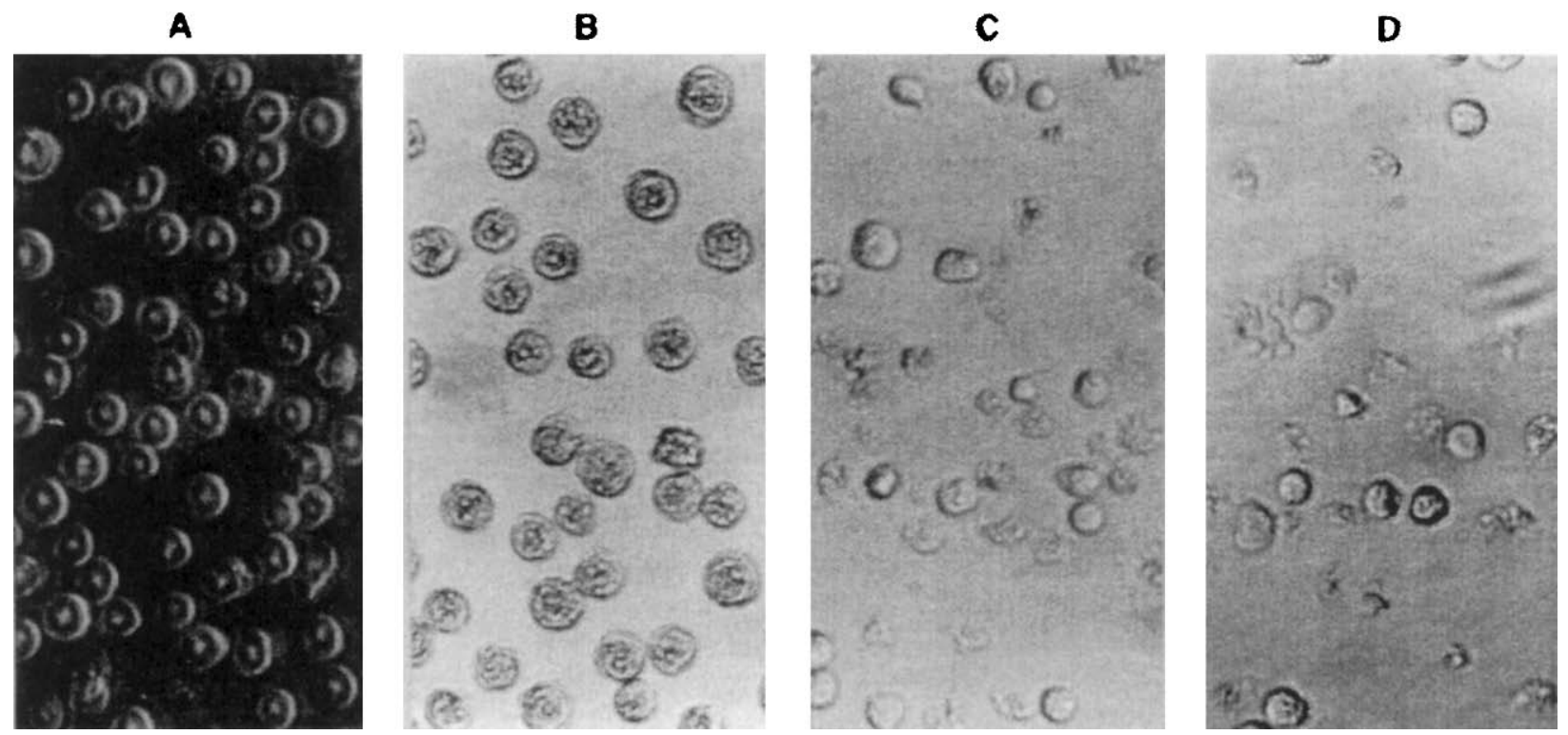

Figure 7. Morphological appearance of HL-60 cells after $24 \mathrm{~h}$ of incubation. Cells were treated in the absence (A) or presence of purified peptides (100 $\mu \mathrm{g} / \mathrm{ml})$; pep1 (B), pep2 (C) and pep4 (D), and then analyzed by light microscopy. 
ies are currently in progress in our laboratory to identify the minimal sequence with high activity by extracting fragments with smaller size from pepsin hydrolysates of bLF.

The death of HL-60 cells induced by the peptides purified in this study was shown to be due to induction of apoptosis demonstrated by fragmentation of nuclei DNA, and of expression of phosphatidyl serine in the outer cellular membrane and marked morphological changes such as cell shrinkage, abnormal chromosome condensation, etc. in HL-60 cells, although a smaller proportion of the cells exhibited necrotic cell death.

The iron chelators mimosine and desferrioxamine that result in iron deprivation are known to block progression through cell cycles (Kulp et al., 1996) or to induce apoptosis (Fukuchi et al., 1994). Iron chelating ability of LF has long been described as an important factor for antibacterial activity but location of Lfcin B, or the peptides purified in this study in bLF were distinct from the iron binding site, indicating that their activities are independent of iron. It has been speculated that the cationic charged groups are very important for the activity of Lfcin B. All three peptides described here were cationic. A recently published report (Aramaki et al., 2000) showed that cationic properties of some compounds such as liposomes induce apoptosis, whereas anionic or negatively charged liposomes were described as inactive. Therefore, the correlation between positively charged groups and induction of apoptosis in HL-60 cells was suggested. However, we showed that pep1-induced apoptosis was related to the formation of superoxide as the apoptotic activity of this peptide was almost completely blocked by the addition of antioxidants such as $\mathrm{N}$-acetylcysteine or glutathione (unpublished data). The mechanism involved in the induction of apoptosis in HL-60 cells by the two other peptides is now under investigation.

Many chemotherapeutic agents have been reported to induce apoptosis or programmed cell death (Barry et al, 1993; Walton et al., 1993; Evans et al., 1993). There is also evidence that the efficiency of anti-tumor agents is related to the propensity of target cells to respond to these agents by apoptosis (Walton et al 1993). Recently, suppression of apoptosis has been shown to be an important factor for tumor promotion in preneoplastic cells (Evans et al., 1993). Oral administration of bLF has also been shown to be very effective against hepatocellular carcinoma (Tanaka et al., 1999). In mice, oral administration of bLF and pepsin hydrolysates of bLF significantly inhibited metatistic colony formation from implanted tumors; however, after oral administration $(300 \mathrm{mg} / \mathrm{kg}$ ) no lactoferrin was detected in serum (Igo et al., 1999). It is very likely that ingested lactoferrin is digested in the gastrointestinal cavity, and the absorbed fragments of lactoferrin provide a source of anti-HCV (hepatitis C virus) activity or antimetastatic activity. Thus, we suggest that apoptosisinducing activity of the peptides may contribute in antitumor activity. Recently a report of Tomita et al. (1994) provided evidence of in vivo production of Lfcin B by isolating the peptides from the gastrointestinal contents of rats fed a diet containing bLF. The peptides characterized in this study can be generated by in vivo digestion of bLF with pepsin or other proteolytic enzymes and may be a useful source of agents with beneficial biological effects.

\section{REFERENCES}

Aramaki, Y., S. Takano, H. Arima and S. Tsuchiya. 2000. Induction of apoptosis in WEHI 231 cells by cationic liposomes. Pharm. Res. 17:515-520.

Arnold, R. R., M. F. Cole, and J. R. McGhee. 1977. A bactericidal effect for human lactoferrin. Science 197:263-265.

Barry, M. A., J. E. Reynolds, and A. Eastman. 1993. Etoposide-induced apoptosis in human HL-60 cells is associated with intracellular acidification. Cancer Res. 53:2349-2357.

Bayly, A. C., R. A. Roberts and C. Dive. 1994. Suppression of liver cell apoptosis in vitro by the non-genotoxic hepatocarcinogen and peroxisome proliferator nafenopin. J. Cell Biol. 125:197-203.

Bellamy, W., M. Takase, H. Wakabayashi, K. Kawase, H. Yamauchi, M. Shimamura and, M. Tomita 1992a. Identification of the bactericidal domain of lactoferrin. Biochim. Biophys. Acta 1121:130136.

Bellamy, W., M. Takase, H. Wakabyashi, K. Kawase and M. Tomita. 1992b. Antibacterial spectrum of lactoferricin B, a potent bactericidal peptide derived from the $\mathrm{N}$-terminal region of bovine lactoferrin. J. Appl. Bacteriol. 73:472-479.

Bellamy, W., M. Takase, H. Wakabayashi, K. Kawase, H. Yamauchi, M. Shimamura, and M. Tomita 1993. Role of cell binding in the antibacterial mechanism of lactoferricin B. J. Appl. Bacteriol. 75:478-484.

Brock, J. 1995. Lactoferrin: a multifunctional immunoregulatory protein? Immunol. Today 16:417-419.

Brunk, C. F., K. C. Jones, and T. W. James. 1979. Assay for nano gram quantities of DNA in cellular homogenates. Anal. Biochem. 92:497-500.

Dionysius, D. A. and J. M. Milne. 1997. Antibacterial peptides of bovine lactoferrin. J. Dairy Sci. 80:667-674.

Ellison, R. T., F. M. Laforce, T. J. Giehl, D. S. Boos, and B. E. Dunn. 1990. Lactoferrin and transferrin damage of the gram-negative outer membrane is modulated by $\mathrm{Ca} 2+$ and $\mathrm{Mg} 2+$. J. Gen. Microbiol. 136:1437-1446.

Ellison, R. T., T. J. Giehl, and F. M. LaForce. 1988. Damage of the outer membrane of enteric gram-negative bacteria by lactoferrin and transferrin. Infect. Immunol. 56:2774-2781.

Evans D. L., and C. Dive. 1993. Effects of cisplatin on the induction of apoptosis in proliferating hepatoma cells and nonproliferating immature thymocytes. Cancer Res. 53:2133-2139.

Fukuchi, K., S. Tomoyasu, N. Tsuruoka, and K. Gomi. 1994. Iron deprivation-induce apoptosis in HL-60 cells. FEBS Lett. 350:139-142.

Igo, M., T. Kuhara, Y. Ushida, K. Sekine, M. A. Moore, and H. Tsuda. 1999. Inhibitory effects of bovine lactoferrin on colon carcinoma 26 lung metastasis in mice. Clinical Exp. Metastasis 17:35-40.

Ito, M., M. K. Roy, T. Kurihara, Y. Watanabe, Y. Kuwabara, S. Nagai, and Y. Tamai. 1998. Effects of bovine milk fermented by culturing with lactic acid bacteria and a yeast on the proliferation activity of human carcinoma cells. Food Sci. Int. Tokyo 4:125-129.

Kulp, K. S., S. L. Green, and P. R. Vulliet. 1996. Iron deprivation inhibits cyclin-dependent kinase activity and decrease cyclin D/ 
CDK4 protein levels in asynchronous MDA-MB-453 human breast cancer cells. Exp. Cell Res. 229:60-68.

Laurent-Crawford, A. G., B. Krust, S. Muller, Y. Riviere, M. A., ReyCuille, J. M. Bechet, L. Montagnier, and A. G. Hovanessian. 1991. The cytopathic effect of HIV is associated with apoptosis. Virology 185:829-839.

Pierce, G. B., A. L. Lewellyn, and R. E. Parchment (1989). Mechanism of programmed cell death in the blastocyst. Proc. Natl. Acad. Sci. USA 86:3654-3658.

Recio, I., and S. Visser. 1999. Two ion-exchange chromatographic methods for the isolation of antibacterial peptides from lactoferrin. In situ enzymatic hydrolysis on an ion-exchange membrane. J. Chromatogr. A 831:191-201.

Roy, M. K., Y. Watanabe, and Y. Tamai. 1999. Induction of apoptosis in HL-60 cells by skimmed milk digested with a proteolytic enzyme from the yeast Saccharomyces cerevisiae. J. Biosci. Bioeng. $88: 426-432$.
Tanaka, K., M. Ikeda, A. Nozaki, N. Kato, H. Tsuda, S. Saito, and H. Sekihara. 1999. Lactoferrin inhibits hepatitys C virus viremia in patients with chronic hepatitis C: A pilot study. Jpn. J. Cancer Res. 90:367-371.

Tomita, M., M. Takase, W. Bellamy, and S. Shimura. 1994. A review: the active peptide of lactoferrin. Acta Paediatr. Jpn. 36:585.

Ucker, D. S. 1987. Cytotoxic T lymphocytes and glucocorticoids activate an endogenous suicideprocess in target cells. Nature 327:62-64.

Vaux, D. L., S. Cory, and J. M. Adams. 1988. Bcl-2 gene promotes haemopoietic cell survival and cooperates with c-myc to immortalize ppre-B cells. Nature 335:440-442.

Walton, M. I., D. Whysong, P. M. O'Conner, D. Hokenbery, S. J. Korsmeyer, and K. W. Kohn. 1993. Constitutive expression of human Bcl-2 modulates nitrogen mustard and camptothecin induced apoptosis. Cancer Res. 53:1853-1861.

Wyllie, A. H. 1980. Glucocorticoid-induced thymocyte apoptosis is associated with endogenous endonuclease activation. Nature 284:555-556. 